\author{
Н. Г. МАЛЫШ ${ }^{1}$ С. И. ДОАН ${ }^{2}$, О. Н. ЧЕМИЧ
}

\title{
РОТАВИРУСНАЯ ИНФЕКЦИЯ В УКРАИНЕ: ОСОБЕННОСТИ ЭПИДЕМИОЛОГИИ
}

\author{
${ }^{1}$ Сумской государственный университет; \\ ${ }^{2}$ Киевский медицинский университет НАНМ Украины
}

\begin{abstract}
В современных условиях в Украине официальные показатели заболеваемости ротавирусной инфекцией варьируют от 14,7 до 30,9 на 100000 населения и превышают иниидентность шигеллёзом и сальмонеллёзом. Группа риска - дети в возрасте до 4 лет. Уровни заболеваемости ротавирусной инфекцией детей в возрасте до 1 года превъшают иниидентность детей 5-9 лет более чем в 6 раз, 10-14 лет - более чем в 30 раз, 15-17 лет - более чем в 100 раз. Инцидентность городских жителей в 3 раза выше сельских. Чаще всего ротавирусную инфекиию регистрируют в областях, расположенных в бассейне реки Днепр и акватории Чёрного моря. В детских дошкольных учреждениях зарегистрировано большинство (66,7 \%) вспьшек ротавирусного энтерита. Увеличение заболеваемости отмечается в зимние месяцы. Масштабность водных вспышек зависит от типа источника питьевого водоснабжения.
\end{abstract}

Ключевые слова: ротавирусная инфекция, эпидемический процесс, заболеваемость.

В настоящее время изменилась этиологическая структура острых кишечных инфекций (ОКИ). Заболеваемость классическими бактериальными кишечными инфекциями значительно уменьшилась [2]. Эту образовавшуюся «экологическую нишу» заполнили вирусные кишечные заболевания, возбудители которых устойчивы во внешней среде, не требовательны к факторам передачи и способны к реализации инфекции через самые разнообразные механизмы и пути заражения. Ротавирусная инфекция (РВИ) - самая массовая кишечная инфекция практически на всей территории Земного Шара $[5,6]$. Важнейшими возбудителями являются ротавирусы (РВ) антигенной группы А, вызывающие у детей 30-50 \% острого гастроэнтерита [7]. Высокий уровень заболеваемости обусловлен периодической сменой $\mathrm{G}[\mathrm{P}]$ - типов $\mathrm{PB}$, генетическим и антигенным разнообразием вируса [8].

Важное социально-экономическое значение инфекции требует совершенствования эпидемиологического надзора и планирования рациональных профилактических мероприятий. Ряд важных вопросов эпидемиологии инфекции исследован недостаточно: существуют противоречивые мнения по вопросу эпидемиологической значимости различных путей передачи РВ. В условиях неполного выявления РВИ отсутствуют чёткие представления о текущей эпидемиологической ситуации, не разработаны методические подходы к прогнозированию подъёмов заболеваемости [1, 4].

Цель исследования - изучить этиологическую структуру ОКИ в Украине в современных условиях, установить особенности эпидемического процесса (ЭП) РВИ.

Материалы и методы. В работе использованы материалы официальной статистики Главного управления санитарно-эпидемиологической службы Украины в 2010-2015 гг. (ф. №1, ф. №2 «Сведения об инфекционных и паразитарных заболеваниях», ф. №23 «Сведения о вспышках инфекционных заболеваний»), отчётов вирусологической лаборатории Сумского областного лабораторного центра Госсанэпидслужбы Украины. Основными методами исследования были эпидемиологический и статистический анализы, в рамках которого проанализирована динамика многолетней заболеваемости ОКИ, групповые показатели инцидентности, территориальное распределение, вспышки заболеваемости РВИ. Статистическую обработку полученных результатов проводили с применением пакета C-STAT (Oxford Statistic). 
Результаты и их обсуждение. В Украине в 2010-2015 гг. чаще всего регистрировали пищевые токсикоинфекции, ОКИ, вызванные условно-патогенными микроорганизмами и вирусами, которые в официальной медицинской отчётности Минздрава Украины объеденены в группу «Пищевые токсикоинфекции, гастроэнтериты, энтериты, колиты, вызванные другими установленными возбудителями» (ОКИУЭ) (рис. 1). Уровни заболеваемости вышеуказанными инфекциями варьировали в пределах 115,1-123,3 на 100000 населения. ЭП ОКИУЭ характеризовался стабильными показателями без тенденции к снижению.

Инцидентность другими кишечными инфекциями, подлежащими обязательной регистрации в Украине, была значительно ниже. Из ОКИ бактериальной этиологии, вызванных патогенными микроорганизмами, чаще всего выявляли сальмонеллёз. Показатели инцидентности сальмонеллёзом находились в пределах 19,524,1 на 100000 населения ( $\left.\mathrm{T}_{\text {сн. ср. }}=-0,14 \%\right)$. Уровень заболеваемости шигеллёзом варьировал от максимального - 6,1 на 100000 населения в 2012 г. до минимального $-2,2$ в 2015 г. $\left(\mathrm{T}_{\text {сн. ср }}=-5,3 \%\right)$. Инцидентность брюшным тифом находилась в диапазоне 0,01-0,03 на 100000 населения, кампилобактериальным энтеритом $0,19-0,32$, кишечным ерсиниозом - 0,15-0,22 на 100000 населения. Случаи холеры были выявлены лишь в 2011 г. (показатель заболеваемости составил 0,07 на 100000 населения).

В структуре диарейных инфекций значительную часть (от 33,3 до 40,3%) составляли ОКИ неустановленной этиологии (ОКИНЭ). При этом показатель заболеваемости ОКИНЭ за последние 6 лет увеличился более чем на 28 \%, а средний ежегодный темп прироста составил $+15,3 \%$.

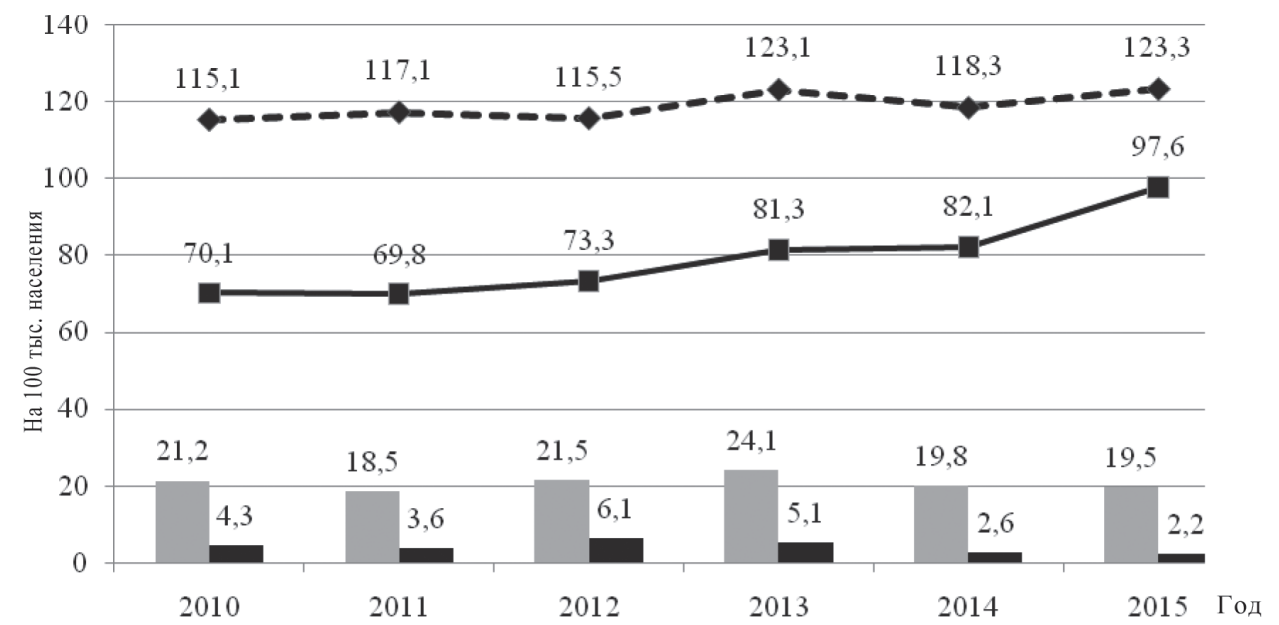

Рис. 1. Динамика заболеваемости кишечными инфекциями в Украине

- сальмонеллёз; - шигеллёз; - - - - ОКИУЭ; - - ОкИнЭ

Поскольку исследования для детекции вирусов в клиническом материале проводили в Украине лишь в отдельных случаях, избирательно, считаем, что вероятнее всего диарейные инфекции, зарегистрированные как ОКИНЭ, в большинстве случаев имели вирусное происхождение. Это предположение опосредованно подтвердили результаты проведённого нами анализа данных отчётов вирусологической лаборатории Сумского областного лабораторного центра. Из образцов фекалий (всего 407) РВ были изолированы в $(41,4 \pm 3,5)$ \% случаев, аденовирусы - в $(26,6 \pm 3,9) \%$, норо-, энтеро- и астровирусы - соответственно в $(26,8 \pm 6,9) \%$; $(10,0 \pm 2,9) \%$ и $(3,9 \pm 1,7) \%$. Между частотой выявления РВ от больных ОКИ и показателями заболеваемости ОКИНЭ установлена прямая сильная корреляционная связь $(r=0,809)$.

Регистрация случаев ротавирусного энтерита (РВЭ) в Украине начата с 1995 г. С этого времени показатели заболеваемости постоянно повышались, что, по на- 
шему мнению, обусловлено прежде всего совершенствованием лабораторной диагностики ОКИ. С целью выявления вирусов в региональных лабораториях стали использовать иммуноферментный и иммунохроматографический анализы, метод полимеразно-цепной реакции. В 2010-2015 гг. официально зарегистрированная заболеваемость РВИ в Украине находилась в пределах 14,7-30,9 на 100000 населения и превышала ( $\mathrm{P}<0,05)$ инцидентность шигеллёзом в 2010 г. в 3,4 раза, в 2011 г. - в 5,3 раза, в 2012 г. в - 3,2 раза, в 2013 г. - в 4,8 раза, в 2014 и 2015 гг. в 11,9 и 13 раз соответственно (рис. 2). В 2014 и 2015 гг. показатели заболеваемости сальмонеллёзом также были ниже соответственно в 1,6 и 1,5 раза. Кроме того, удельный вес РВЭ в общей структуре зарегистрированных ОКИ увеличился с $6,9 \%$ в 2010 г. до 11,9\% в 2015 г.

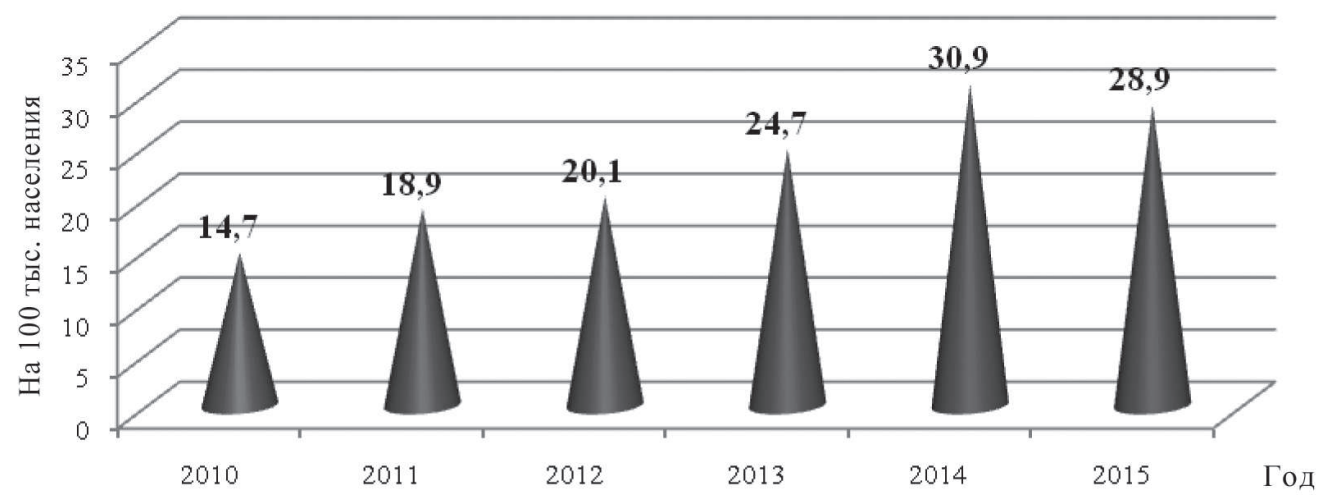

Рис. 2. Динамика заболеваемости ротавирусной инфекцией в Украине

Известно, что контингентом риска заболеваемости РВИ является детское население [5, 6]. В Украине в течение исследованного периода наиболее высокие уровни инцидентности РВИ наблюдали у детей в возрасте до 1 года (показатели находились в диапазоне 367,8-504,9 на 100000 контингента) и 1-4 года (в пределах 316,1-465,0 на 100000 контингента) (табл. 1). Зарегистрированная инцидентность в возрасте 5-9 лет была ниже более чем в 6 раз, в возрасте 10-14 лет - более чем в 30 раз, в возрасте 15-17 лет - более чем в 100 раз. Зарегистрированные показатели заболеваемости взрослых находились в пределах 0,7-1,1 на 100000 взрослого населения.

Таблица 1. Динамика заболеваемости ротавирусной инфекцией детского и взрослого населения Украины (на 100000 контингента)

\begin{tabular}{c|c|c|c|c|c|c|c}
\hline \multirow{2}{*}{ Год } & \multicolumn{7}{c}{ Показатель заболеваемости } \\
\cline { 2 - 7 } & $\begin{array}{c}\text { дети до } \\
\text { 1 года }\end{array}$ & $\begin{array}{c}\text { дети } \\
\text { 1-4 лет }\end{array}$ & $\begin{array}{c}\text { дети } \\
\text { 5-9 лет }\end{array}$ & $\begin{array}{c}\text { дети } \\
\text { 10-14 лет }\end{array}$ & $\begin{array}{c}\text { дети } \\
\text { 15-17 лет }\end{array}$ & $\begin{array}{c}\text { дети до } \\
17 \text { лет }\end{array}$ & \multirow{2}{*}{ взрослые } \\
\hline \hline 2012 & 367,8 & 316,1 & 39,9 & 4,8 & 1,9 & 110,7 & 0,7 \\
2013 & 440,5 & 385,0 & 46,6 & 6,5 & 1,6 & 136,9 & 0,8 \\
2014 & 491,8 & 465,0 & 69,9 & 12,6 & 3,5 & 171,1 & 0,9 \\
2015 & 504,9 & 421,3 & 64,1 & 10,3 & 4,4 & 158,2 & 1,1 \\
\hline
\end{tabular}

Нами была установлена корреляционная зависимость между уровнями заболеваемости РВИ у малышей до 1 года и детьми в возрасте $1-4$ лет $(r=0,931)$, 5-9 $(r=0,923), 10-14(r=0,896)$ и 15-17 лет $(r=0,816)$. Прямая связь, хотя и меньшей силы, также была выявлена между инцидентностью детей и взрослых $(r=0,549)$. Поэтому увеличение заболеваемости РВИ в одной возрастной группе неизбежно приводит к повышению инцидентности в другой. Вышеуказанная эпидемиологическая особенность РВИ связана, по нашему мнению, с основным путём передачи инфекции - контактно-бытовым. Эффективное инфицирование окру- 
жения больного и носителя обусловлено низкой заражающей дозой РВ и массивной контаминацией предметов окружающей среды. Лица старшего возраста, имея постинфекционный поливалентный иммунитет, являются основным резервуаром $\mathrm{PB}$, участвуя в их эпидемическом распространении.

Городские жители в Украине болели РВИ гораздо чаще сельских. Показатели заболеваемости в городах превышали уровни инцидентности в сёлах более чем в 3 раза и варьировали в диапазоне 207,4-427,6 на 100000 населения (табл. 2), т. е. заражение РВ неизбежно при ежедневных контактах которых намного больше в городе.

Таблица 2. Динамика заболеваемости ротавирусной инфекции городского и сельского населения Украины (на 100000 контингента)

\begin{tabular}{l|c|c|c|c|c|c}
\hline \multirow{2}{*}{ Категория населения } & \multicolumn{7}{|c}{ Год } \\
\cline { 2 - 7 } & 2010 & 2011 & 2012 & 2013 & 2014 & 2015 \\
\hline \hline Жители городов & 207,4 & 287,7 & 325,8 & 365 & 427,6 & 313,8 \\
Жители села & 39,9 & 62,8 & 62,8 & 45 & 138,6 & 39,6 \\
\hline
\end{tabular}

РВИ в Украине распространена по всей территории. Однако частота её регистрации в регионах Украины отличается в десятки раз. Чаще всего РВЭ регистрировали в Запорожской (127,6 на 100000 населения), Днепропетровской (39,8 на 100000 населения), Одесской (36,3 на 100000 населения), Херсонской (36,1 на 100000 населения), Николаевской (33,3 на 100000 населения) и Полтавской (30,8 на 100000 населения) областях, которые территориально расположены у берегов Чёрного моря и в бассейне реки Днепр. Жители регионов, которые использовали воду Днепра как питьевую и для хозяйственных нужд, болели РВЭ чаще, чем остальное население Украины.

Учитывая вышеизложенное, можем предположить, что всё-таки водный путь передачи возбудителя РВИ является одним из главных, и это в какой-то мере противоречит опубликованным данным о том, что в воде РВ теряет инфекционность [3].

ОКИ - наиболее значимая группа болезней, ответственная за формирование эпидемических очагов. Сведения о вспышках заболеваемости имеют большое значение для оценки эпидемиологической ситуации. В Украине в 2015 г. РВ как возбудитель монопатоген зарегистрирован в $(14,9 \pm 3,5)$ \% случаев вспышек ОКИ (всего 101) и в $(13,3 \pm 8,8) \%$ случаев - в ассоциации с другими микроорганизмами. В $(66,7 \pm 12,2) \%$ случаев вспышки РВЭ выявлены в детских дошкольных учреждениях (ДДУ), в $(20,0 \pm 10,3) \%$ - в школах и колледжах, в $(13,3 \pm 8,8) \%$ среди населения, употреблявшего загрязнённую воду. Количество заболевших РВИ детей в очагах, возникших в ДДУ, варьировало от 3 до 10. Во вспышечный процесс, в котором вода послужила фактором передачи РВ, было вовлечено значительно больше лиц: в Киеве - 54 и в с. Оженино Ровненской области - 19. Эпидемические очаги РВЭ в ДДУ существовали в среднем до 9 дней, водные вспышки - от 7 до 25 дней. В зимне-весенне-осенний период зарегистрировано 86,6 \% вспышек РВИ.

Причинами вспышек в ДДУ было нарушение санитарно-противоэпидемического режима в группах и на пищеблоке, несоблюдение детьми правил личной гигиены. При расследовании водной вспышки в Киеве выявлено неудовлетворительное санитарно-техническое состояние сети централизованного водоснабжения, в с. Оженино - загрязнение колодца сточными водами.

Таким образом, на современном этапе РВИ является актуальной инфекцией, имеющей тенденцию к вспышкам заболеваемости. Повышения заболеваемости следует ожидать с осени. Среди факторов передачи особое место занимает вода. Масштабность водной эпидемии зависит от того, какой источник питьевого водоснабжения окажется инфицированным. 
Выводы. 1. На современном этапе в Украине уровень заболеваемости РВИ составляет 14,7-30,9 на 100000 населения и превышает инцидентность шигеллёзом и сальмонеллёзом. 2. Превалирующими путями передачи РВИ являются контактно-бытовой и водный. 3. Наиболее высокие показатели заболеваемости РВИ выявлены в группе детей в возрасте до 4 лет (от 316,1 на 100000 контингента до 491,8). 4. В условиях выборочных обследований показатель удельного веса выявления РВ из клинического материала может служить дополнительным маркёром в оценке эпидемиологической ситуации по РВИ. 5. Надзор и контроль за ОКИ вирусной этиологии, в том числе РВИ, требуют в современных условиях более широкого внедрения методов экспресс-диагностики, совершенствования профилактических мероприятий.

\section{С пи с ок ли т е рат у ры}

1. Зарубинский В. Я., Ловердо Р. Г., Егоренкова И. Л. Вопросы эпидемиологической диагностики ротавирусной инфекции // Эпидемиология и инфекционные болезни. -2012 . - № 1. - С. 30-34.

2. Малыш Н. Г., Доан С. И., Холодило Е. В. и др. Нозологическая структура острых кишечных инфекций. Эндогенные факторы риска // Иммунопатология. Аллергология. Инфектология. - 2015. - № 3. - С. 40-46.

3. Новикова Н. А., Епифанова Н. В., Романова T. B. Ротавирусный гастроэнтерит. Противоэпидемические мероприятия: Пособие для врачей. - Н. Новгород, 1998. - 16 с.

4. Тхакушинова Н.X. Ротавирусная инфекция у детей // Эпидемиология и инфекционные болезни. - 2012. - № 2. - С. 56-59.

5. Черепанова Е.А., Чернявская О.П., Морозова Н. С., Ясинский А. А. Особенности эпидемиологии ротавирусной инфекции в Российской Федерации в 2000-2010 годах // Эпидемиология и вакцинопрофилактика. - 2012. - № 2. - С. 38-41.
1. Zarubinskiy V. Ya., Loverdo R. G., Egorenkova I. L. Voprosy epidemiologicheskoy diagnostiki rotavirusnoy infektsii // Epidemiologiya i infektsionnyye bolezni. - 2012. № 1. $-\mathrm{S}$. 30-34.

2. Malysh N. G., Doan S. I., Kholodilo E. V. i dr. Nozologicheskaya struktura ostrykh kishechnykh infektsiy. Endogennyye faktory riska // Immunopatologiya. Allergologiya. Infektologiya. - 2015. - № 3. - S. 40-46.

3. Novikova N. A., Epifanova N. V., Romanova $T$. $V$. Rotavirusnyy gastroenterit. Protivoepidemicheskiye meropriyatiya: Posobiye dlya vrachey. - N. Novgorod. 1998. -16 s.

4. Tkhakushinova N. Kh. Rotavirusnaya infektsiya u detey // Epidemiologiya i infektsionnyye bolezni. - 2012. - № 2. - S. 56-59.

5. Cherepanova E. A., Chernyavskaya O.P., Morozova N. S., Yasinskiy A. A. Osobennosti epidemiologii rotavirusnoy infektsii v Rossiyskoy Federatsii v 2000-2010 godakh // Epidemiologiya i vaktsinoprofilaktika. 2012. - № 2. - S. 38-41.

6. Bruun T., Salamanca B. V., Bekkevold T. Norwegian Enhanced Pediatric Immunisation Surveillance (NorEPIS) Network. Burden of Rotavirus Disease in Norway: Using National Registries for Public Health Research // Pediatr. Infect. Dis J. - 2016. - Vol. 35, N 4. - P. 396-400.

7. Ianiro G., Deloqu R., Bonomo P. Molecular analysis of group A rotaviruses detected in adalts and adolescents with severe acute gastroenteritis in Italy in 2012 // J. Med. Virol. - 2014. - Vol. 86, N 6. - P. 1073-1082.

8. Sarkar S. R., Hossain M. A., Paul S. K. Rotavirus is Predominent Enteropathogen in Acute Childhood Diarrhea in Mymensingh // Mymensingh. Med. J. - 2015. - Vol. 24, N 4. - P. 665-670.

\section{РОТАВІРУСНА ІНФЕКЦІЯ В УКРАЇНІ: ОСОБЛИВОСТІ ЕПІДЕМІОЛОГІЇ}

\section{Н. Г. Малии, С. І. Доан, О. М. Чемич (Суми, Київ)}

В сучасних умовах в Україні офіційні показники захворюваності на ротавірусну інфекцію варіюють від 14,7 до 30,9 на 100000 населення і перевищують інцидентність на шигельоз і сальмонельоз. Група ризику - діти у віці до 4 років. Рівень захворюваності на ротавірусну інфекцію дітей у віці до 1 року перевищує інцидентність дітей 5-9 років у понад 6 разів, 1014 років - у 30 разів, 15-17 років - у 100 разів. Інцидентність міських жителів у 3 рази вища сільських. Найчастіше ротавірусну інфекцю реєструють в областях, розташованих у басейні річки Дніпро і акваторії Чорного моря. У дитячих дошкільних установах зареєстровано більшість (66,7 \%) спалахів ротавірусних ентеритів. Підвищення захворюваності відбувається у зимові місяці. Масштабність водних спалахів залежить від типу джерела питної води.

Ключові слова: ротавірусна інфекція, епідемічний процес, захворюваність. 


\title{
ROTAVIRUS INFECTION IN UKRAINE: FEATURES OF EPIDEMIOLOGY
}

\author{
N. G. Malysh', S. I. Doan², O. N. Chemych (Sumy, Kyiv; Ukraine)
}

${ }^{1}$ Sumy State University; ${ }^{2} \mathrm{Kiev}$ Medical University of NANS of Ukraine

Under current conditions in Ukraine, the official incidence of rotavirus infection ranges from 14.7 to 30.9 per 100000 population and higher than the incidence of salmonellosis and shigellosis. Risk group - children up to 4 years. Incidence of rotavirus infection in children under 1 year of exceeding the incidence of children 5-9 years more than 6 times, 10-14 years - more than 30 times, 15-17 years - more than 100 times. The incidence of the urban population is 3 times higher in rural areas. The most common rotavirus infection were recorded in the areas located in the Dnipro river basin and the Black Sea. The majority (66.7\%) outbreaks of rotavirus enteritis reported in kindergartens. The rise of the incidence observed in the winter months. The scale of outbreaks of water depends on the type of source of drinking water.

Key words: rotavirus infection, epidemic process, incidence.

\section{Д. Г. РЕКАЛОВ, А. В. ПРЫТКОВА}

\section{КЛИНИЧЕСКОЕ ЗНАЧЕНИЕ БИОМАРКЁРОВ ДЛЯ ДЕТЕРМИНАЦИИ КОСТНО-ХРЯЩЕВОЙ ДЕСТРУКЦИИ НА РАННЕМ ЭТАПЕ РАЗВИТИЯ РЕВМАТОИДНОГО АРТРИТА}

\author{
Кафедра внутренних болезней 3 (зав. - проф. С. Я. Доценко) \\ Запорожского государственного медицинского университета < direc@bigmir.net>

\begin{abstract}
Изучены биомаркёры костно-хрящевой деструкции на максимально раннем этапе развития ревматоидного артрита (РА). Проведена верификация прогностической ценности показателей эрозивно-деструктивных процессов в суставном аппарате при раннем РА и на развёрнутой стадии. Проанализированы показатели, детерминирующие непосредственно как активность инфламматорного процесса, так и ключевые цитокины, ассоциированные с быстротой и стадийностью повреждения суставных поверхностей, что позволяет адекватно обосновать индивидуализированную клиническую тактику у больных ранним $Р A$.
\end{abstract}

Ключевые слова: ранний этап развития ревматоидного артрита, регрессионный анализ, субхондральные эрозии, костно-хрящевая деструкция, биомаркёры.

Актуальность темы. Ревматоидный артрит (РА) - хроническое аутоиммунное заболевание, которое клинически проявляется выраженной болезненностью, припуханием и снижением функций поражённых суставов [5, 9]. Артралгический синдром часто предшествует симптоматике активного воспаления суставов, что может быть связано с высоким титром провоспалительных цитокинов [6, 19]. Костная резорбция является одним из ключевых патологических изменений при PA, и в классических работах считается отражением воспалительных изменений в суставе, что обусловливает важное значение максимально ранней и своевременной диагностики, особенно на раннем этапе [4, 11]. Некоторые проинфламматорные цитокины, которые можно обнаружить в синовиальной жидкости при активном воспалении [2, 22, 23], включая матриксные металлопротеиназы-3 (ММП-3), человеческий гликопротеин с молекулярной массой 39 кДа (YKL-40), ассоциированы с выраженной стимуляцией остеокластов $[10,14,16]$. В доклинической стадии, иногда за несколько месяцев и даже лет до манифестации клинической симптоматики [8], а также на развёрнутой стадии заболевания объективными и адекватными маркёрами патологических деструктивных процессов считают С-конечные телопептиды коллагена I типа сыворотки (СТП-I) и II типа мочи 